\title{
Study protocol: the relation of birth weight and infant growth trajectories with physical fitness, physical activity and sedentary behavior at 8-9 years of age - the $A B C D$ study
}

Arend W van Deutekom ${ }^{1,2^{*}}$, Mai JM Chinapaw ${ }^{3}$, Tanja GM Vrijkotte ${ }^{4}$ and Reinoud JBJ Gemke ${ }^{1,2}$

\begin{abstract}
Background: Low birth weight and accelerated infant growth have been identified as independent risk factors for childhood and adult obesity and cardiovascular disease. This led to the 'Developmental Origins of Health and Disease' (DOHaD) hypothesis, stating that environmental factors during pregnancy and early postnatal life affect disease risk in later life. There is growing evidence that perinatal factors may influence adult health through the programming of energy balance regulation, including sedentary behavior and physical activity. The present study focuses on the influence of birth weight and infant growth on physical fitness, physical activity and sedentary behavior in 8-9 year old children, as this might partly explain the higher obesity and cardiovascular risk associated with low birth weight and accelerated infant growth. In addition, this study provides the opportunity for a validation study of a linguistic and cross-cultural translated physical activity questionnaire compared to accelerometer data. This article describes the study protocol for this study.
\end{abstract}

Methods/Design: This is a study embedded in the Amsterdam Born Children and their Development (ABCD) birth cohort. In 200 children of Dutch ethnicity, physical fitness, physical activity and sedentary behavior were assessed at age 8-9. We measured aerobic fitness using the 20 meter multistage shuttle run test, and neuromuscular fitness using the standing broad jump and handgrip strength test. Sedentary behavior and physical activity levels were measured using accelerometry. All children also completed a translated physical activity questionnaire, the scores of which will be compared to accelerometry data to assess the construct validity of the questionnaire in Dutch school-aged children.

Discussion: This study will be the first population-based prospective cohort study to address the association of both prenatal and postnatal growth with physical fitness and objectively-assessed physical activity and sedentary behavior. This will contribute to a better understanding of the way perinatal growth relate to lifestyle and obesity in later life. The results may guide both future studies in the field of $\mathrm{DOHaD}$, and public health strategies in the prevention of childhood obesity.

Keywords: Developmental origins of health and disease, Birth weight, Child growth, Physical fitness, Muscle strength, Aerobic fitness, Physical activity, Sedentary behavior, Physical activity questionnaire

\footnotetext{
* Correspondence: a.vandeutekom@vumc.nl

${ }^{1}$ Department of Pediatrics, EMGO Institute for Health \& Care Research, VU

University Medical Center, Amsterdam, the Netherlands

${ }^{2}$ Institute for Cardiovascular Research VU, VU University Medical Center,

Amsterdam, the Netherlands

Full list of author information is available at the end of the article
} 


\section{Background}

In the 1980s Barker and Hall reported a series of studies regarding the association between low birth weight and death from coronary heart disease, suggesting that prenatal environmental factors are involved in the aetiology of adult-onset diseases [1,2]. In the following decades numerous epidemiological studies substantiated a close association between low birth weight and an increased risk of developing adult diseases, including cardiovascular disease [3,4], stroke [5], type 2 diabetes mellitus [6], hypertension [7], adiposity [8], osteoporosis [9], polycystic ovarian syndrome [10], depressive disorders [11], and psychoses [12]. These observations led to the 'Developmental Origins of Health and Disease' (DOHaD) hypothesis [13]. This hypothesis proposes that the fetus adapts to a substratelimited intrauterine environment with so called predictive adaptive responses, resulting in permanent changes in tissue differentiation and hormonal and metabolic set points. In this way programming results in irreversible adaptations which enhance survival during postnatal nutritional constraint, but may increase susceptibility to adult-onset diseases in a substrate-rich environment after birth.

As the number of $\mathrm{DOHaD}$ related studies grew, several important additions and refinements to the hypothesis were made. First, an important feature of the epidemiological observations is that adult disease risk is continuous within the normal range of birth weight, rather than being a pathological feature which is expressed below a critical cut-off point [14]. Second, in addition to the role of the intrauterine environment, more recent observations have also drawn attention to the significance of infant growth in the predisposition to adult disease. Accelerated growth in infancy increases risk of obesity [15], type 2 diabetes [16], hypertension [17] and cardiovascular disease [18]. Thus, the critical window for developmental responses may extend into early postnatal life. Last, subtle sex differences in the progression and development of adult diseases are observed, with female offspring being relatively protected from the adverse effects of perinatal malnutrition [19,20]. The cause of this sex difference remains unclear, but a protective effect of female sex hormones is proposed as an intriguing mechanistic explanation.

Obesity plays a critical role in the association between perinatal growth and adult disease, often preceding insulin resistance, dyslipidemia, and hypertension in children and young adults [21]. Given that obesity is fundamentally the result of an inadequate energy balance regulation, in which energy intake exceeds expenditure, its developmental origins cannot be explained by structural changes or neuroendocrine dysregulation alone [22]. Therefore, research on the pathogenesis of obesity has recently focused on the developmental origins of behavior that is closely related to energy expenditure and energy intake, i.e., feeding behavior, physical activity and sedentary behavior.
Physical activity (PA) and sedentary behavior are components of energy expenditure that vary considerably between persons as well as for a given person over time $[23,24]$. Sedentary behavior refers to activities that involve little energy expenditure, such as lying down, sitting, watching television, using the computer and other forms of screen based entertainment [25]. Sedentary behavior is thereby a distinct class of behaviors rather than being the absence of PA.

Both PA and sedentary behavior are of particular interest in the study of the developmental origins of energy balance regulation. Animal studies have shown that offspring of nutritionally impaired pregnancies are significantly less physically active than controls, and show increased sedentary behavior [26-28]. These effects on PA and sedentary behavior seem to originate from programming of the hypothalamic pathways which regulate energy homeostasis [29]. In humans, several clinical studies also identified low birth weight as a predictor for lower PA levels and more sedentary behavior in children and adults [30-34], although others failed to confirm this relationship [35-41], and there are suggestions that the association may be limited to very low birth weight individuals [32].

Physical fitness is generally defined as the ability to perform sports or occupations, and is bidirectionally related to PA [42]. As recent data indicates, regular PA improves physical fitness, and conversely, a high level of physical fitness promotes higher PA levels [43]. It is therefore apparent that unfit children are less inclined to be physically active, which has considerable potential to increase later disease risk. There are many dimensions to fitness, of which aerobic fitness (also known as cardiorespiratory endurance) and muscular strength are most consistently associated with physical performance and cardiovascular health [44-46]. Although fitness can be improved by regular PA, it is partly genetically determined, and perinatal influences may attenuate or strengthen this predetermined fitness level [47]. Indeed, several studies consistently found lower muscle mass and strength in lower birth weight adults and children [48]. For aerobic fitness, the findings are less robust. A number of studies found a significant positive association between birth weight and aerobic fitness in childhood and adulthood [34,49,50], but others did not $[51,52]$. Differences in subject age, sample size, type of fitness test used and severity of growth retardation in the cohort may explain these contradictory reports.

The current evidence suggests that physical fitness and PA may have a combined and accumulative effect on cardiometabolic health from an early age. Especially body fatness is inversely associated with fitness and PA levels [42]. But improved physical fitness and PA also promote a healthier cardiovascular risk profile in children independently from body fatness, including lower blood pressure, higher HDL cholesterol, lower triglycerides, improved 
glucose tolerance and post-prandial lipidemia, and modified clotting factors [42,53]. Therefore, variations in physical fitness and PA might impact future health of children irrespective of obesity risk.

In recent years, sedentary behavior has been identified as a distinct health risk factor. For example, sedentary behavior has been shown to be positively associated with an increased risk of type 2 diabetes, cancer, and all-cause and CVD mortality in adults [54-56]. These associations are shown to be at least partially independent of levels of PA. Reviews of the relationship between sedentary behaviors and obesity in children and adolescents found a positive association, suggesting that sedentary behavior is a risk factor for the development of obesity in children $[57,58]$. Another review, however, concluded there was insufficient evidence for a longitudinal relationship between childhood sedentary time and cardiovascular health indicators, because of a lack of high quality studies addressing this topic [59].

Based on the aforementioned data, we hypothesize that low birth weight and accelerated infant growth is associated with lower levels of aerobic fitness, muscular strength and PA and more time spent on sedentary behavior in school aged children, contributing to the increased propensity to obesity and related diseases in later life. The hypothesized model is shown graphically in Figure 1.

This paper describes the rationale and design of a study aiming to examine the association of birth weight and infant growth trajectories with aerobic fitness, muscular strength and objectively assessed sedentary behavior and PA levels in 8-9 year old children. In order to assess whether an accurate assessment of regular PA can be obtained by self-report questionnaires in Dutch children, we will additionally validate a linguistic and cross-cultural translation of a commonly used PA questionnaire in 8-9 year old children. If validity of this questionnaire has been confirmed in our subgroup, we may use it to assess PA and sedentary behavior of our entire cohort in a future phase of the ABCD study. This article outlines the development of this PA questionnaire.

\section{Study objectives}

The primary study objectives are to examine the association of birth weight and infant growth trajectories with (i) aerobic fitness assessed by the 20 meter multistage shuttle run test (20-m MSRT), (ii) muscular strength assessed by the standing broad jump (SBJ) and hand grip strength test, and (iii) physical activity levels and sedentary time assessed by accelerometry, at 8 to 9 years of age. We will control for potential confounders, such as maternal factors (e.g., maternal age, pre-pregnancy body-mass index (BMI), maternal height, socio-economic status) and child factors (e.g., gender, age, height, BMI, gestational age, Apgar score), and test for possible effect modification by gender. (see Table 1) A secondary objective is to examine the construct validity of a self-report extensive PA questionnaire, based on the internationally employed Physical Activity Questionnaire for Older Children (PAQ-C) and Children's Leisure Activities Study Survey (CLASS). This PA questionnaire is provided in the appendix (see Additional file 1).

\section{Methods/Design Setting}

This study is embedded in the Amsterdam Born Children and their Development (ABCD) study, a prospective birth cohort study aimed at the identification of prenatal and early life influences on health at birth and in later life. The project is carried out by a multidisciplinary team of researchers from the Public Health Service Amsterdam, the Academic Medical Center and VU University Medical Center.

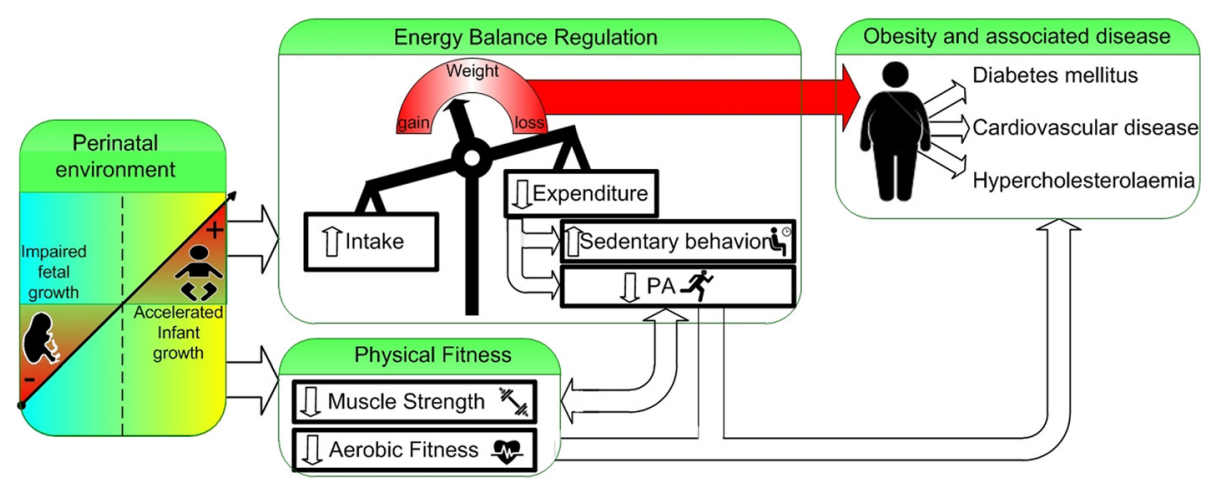

Figure 1 Hypothesized model of the perinatal influences on later disease through energy balance and fitness. Graphical representation of the hypothesized associations of the perinatal environment with obesity and associated diseases through physical fitness, physical activity and sedentary behavior Abbreviations: PA, Physical activity. 
Table 1 Overview of study variables

\begin{tabular}{|c|c|c|c|c|c|}
\hline $\begin{array}{l}\text { Study outcome } \\
\text { construct }\end{array}$ & Component & Test(s) (unit) & $\begin{array}{l}\text { Determinants } \\
\text { construct }\end{array}$ & Variable(s) (unit) & $\begin{array}{l}\text { Potential confounders } \\
\text { Variable(s) (unit) }\end{array}$ \\
\hline \multirow[t]{12}{*}{ Physical fitness } & \multirow[t]{7}{*}{ Aerobic fitness } & \multirow{7}{*}{$\begin{array}{l}20 \text { meter multistage shuttle } \\
\text { run test (stage) }\end{array}$} & \multirow{7}{*}{$\begin{array}{l}\text { Intra-uterine } \\
\text { growth }\end{array}$} & \multirow[t]{7}{*}{ Birth weight (SD) } & Subject-specific: \\
\hline & & & & & - Gender (male/female) \\
\hline & & & & & - Age (years) \\
\hline & & & & & - Height (cm) \\
\hline & & & & & $\cdot$ BMI $\left(\mathrm{kg} / \mathrm{m}^{2}\right)$ \\
\hline & & & & & - Gestational age (days) \\
\hline & & & & & - Apgar score (score at 5 min) \\
\hline & \multirow[t]{5}{*}{ Muscular strength } & \multirow{5}{*}{$\begin{array}{l}\text { Hand grip strength test }(\mathrm{kg}) \\
\text { Standing Broad Jump test }(\mathrm{cm})\end{array}$} & \multirow[t]{5}{*}{ Infant growth } & \multirow{5}{*}{$\begin{array}{l}\text { Average standardized } \\
\text { growth velocity 0-12 } \\
\text { months ( } \Delta \text { SDS) }\end{array}$} & Family-specific: \\
\hline & & & & & - Maternal age (years), \\
\hline & & & & & - Maternal height $(\mathrm{cm})$ \\
\hline & & & & & • Pre-pregnancy BMI (kg/m²), \\
\hline & & & & & - Socio-economic status (class) \\
\hline \multirow[t]{2}{*}{ Physical activity } & \multirow{2}{*}{$\begin{array}{l}\text { Moderate to vigorous } \\
\text { physical activity }\end{array}$} & Accelerometry (minutes/day) & & & \\
\hline & & PA questionnaire (score) & & & \\
\hline \multirow[t]{2}{*}{ Sedentary behavior } & \multirow[t]{2}{*}{ Sedentary time } & Accelerometry (minutes/day) & & & \\
\hline & & PA questionnaire (score) & & & \\
\hline
\end{tabular}

Overview of the primary study outcomes (left column) and determinants (middle column). Described are the studied constructs with the corresponding tests and units of measurement. The right column displays the potential confounders we will control for. Abbreviations: $\mathrm{kg}$, kilograms; $\mathrm{cm}$, centimeters; SD, Standard Deviations; $\triangle S D S$, Difference in Standard Deviation Scores.

The design and conceptual framework of the overall ABCD-study has been previously described in detail [60]. In summary and relevant to the current study, the ABCD-study included 8266 women pregnant between January 2003 and March 2004. These woman completed questionnaires during and after their pregnancies, covering sociodemographic data, lifestyle, dietary habits and psychosocial factors, conventional medical and obstetric history, and perinatal details. Birth weight of the children was obtained from the Child Health Care Registration, the office that also performs neonatal blood screening for inborn errors of metabolism, as is routinely performed in the Netherlands in the $1^{\text {st }}$ week of life. Until the age of 4 years, height and weight measures of these children were routinely collected as part of regular preventive Child Health Care. These measurements took place during on average 14 regular follow-up moments and were performed by qualified nurses and physicians. Of the 6735 women who gave permission for follow-up of their child, 6575 mothers also consented to follow up of their child's growth data.

In 2008 , around their $5^{\text {th }}$ birthday, 3321 children completed a 'health check'. At the appointment for this health check we collected data on anthropometrics, blood pressure, heart rate variability, body composition and a capillary blood sample to determine lipid profile, glucose, insulin, C-peptide, HbA1c and albumin. In addition, parents completed questionnaires about the child's health, development and behavior, family socio-demographics, maternal lifestyle and psychosocial conditions and family history of medical conditions.

\section{Birth weight and infant growth}

The primary determinants in our study are birth weight and infant growth trajectories. Birth weight is hereby used as a surrogate marker for intrauterine growth, and an established index for the intrauterine environment.

Birth weight is expressed as standard deviation (SD) score, adjusted for maternal height, weight, parity, ethnicity and fetal sex, in accordance with the recommendations of Gardosi [61]. Low birth weight is defined as a birth weight below the $10^{\text {th }}$ percentile $(-1.28 \mathrm{SD})$. Infant growth is expressed as the average standardized growth velocity, defined as the change in SD score between birth and 12 months. We will examine growth in weight-for-age, heightfor-age and weight-for-height. We expect the association with the outcome measures to differ for each expression of growth, with the strongest association for weight-for-age. Accelerated growth is defined as $>0.67$ change in SD score. This 0.67 SD represents the distance between two adjacent growth lines on standard infant and childhood growth charts (i.e., the $2^{\text {nd }}, 10^{\text {th }}, 25^{\text {th }}, 50^{\text {th }}, 75^{\text {th }}, 90^{\text {th }}$ and $98^{\text {th }}$ centile lines). The adopted definitions of low birth weight and accelerated infant growth are based on recommendations of Monteiro et al. [15], and in line with recent other studies addressing the DOHaD hypothesis [62-65]. 


\section{Current study population}

The current study is conducted in a subgroup of the ABCD-birth cohort. At the time of the data collection, the children were 8 or 9 years of age. Children were eligible for this study if (i) they fully completed the ABCD age 5 health check and (ii) were of Dutch ethnicity (i.e. with both parents born in the Netherlands). This is to exclude confounding by ethnicity. Exclusion criteria were (i) a personal history of neurological, cardiovascular or metabolic disease, (ii) any musculoskeletal injury or disability or (iii) the use of any medication at the time of data collection.

\section{Sample size calculation}

Based on the literature, we expected to find a difference between low birth weight and normal birth weight children of 1 stage on the 20-m MSRT, with a SD of 2 stages $[49,66]$, and a difference of $10 \mathrm{~cm}$ on the SBJ test, with a SD of 25 $\mathrm{cm}$ [67]. A similar difference in 20-m MSRT and SBJ test scores between children with normal and accelerated infant growth was anticipated, but as there is no literature on this topic available, a scientific basis for this assumption is lacking. With a significance level of $5 \%$ and a power of $80 \%$ in total 100 children per group were required.

\section{Recruitment}

To ensure an adequate number of children in each subgroup, we selected more children with low birth weight and/or accelerated growth than that would be selected by random sampling. This to ensure power of the study that may be lost in a more generalized sampling technique.

A recruitment letter, explaining study objective and design in detail, was sent to all children's parents. For the children, simplified written information was provided. Informed and written consent were obtained from parents before participation. The Amsterdam Medical Center's Ethics Committee approved the study protocol, and all procedures were performed in accordance with the ethical standards of the Helsinki Declaration of 1975 as revised in 2008 [68].

\section{Study design}

Three identical measurement periods were arranged two or three weeks apart. Each measurement period consisted of (A) the self-completion of a PA questionnaire, (B) a physical fitness test battery, and $(C)$ wearing an accelerometer for 7 consecutive days.

\section{A. Modified physical activity questionnaire}

After written consent was obtained, a PA questionnaire was sent to the children by surface mail. The questionnaire was completed at home and handed back at the day of the physical fitness test battery. Responses were checked for completeness by staff.
The PA questionnaire is a cross-cultural adaptation of the Physical Activity Questionnaire for Older Children (PAQ-C) [69] and the Children's Leisure Activities Study Survey (CLASS) [70]: two standardized activity questionnaires for children, both of which recall activities over the previous 7 days.

The PAQ-C is a 7-day self-reported recall instrument, developed to assess general levels of PA throughout the elementary school year for children approximately 8 to 14 years of age [71]. It provides a summary PA score derived from nine items. Each question is scored on a 5point scale, with higher scores indicating higher levels of activity. The first question is a checklist of 22 common leisure and sports activities. Because the PAQ-C only assesses the frequency of activities, we added elements of the CLASS addressing duration of the activities. For each PA in the checklist, children were asked to report the frequency and duration spent in that activity. The next six items addresses PA during physical education classes, recess, lunch break, right after school, in the evenings, and on the weekend. Item eight asks which statement "describes you best for the last 7 days" with five statements describing low to very high activity levels. The ninth item asks the child how often he/she participated in PA on each day of the week [69].

The PAQ-C is widely accepted [72-74] and recommended [75] for international and national studies. In addition, a systematic review of measurement properties of self-report PA questionnaires for children concluded good to moderate validity and reliability of the PAQ-C [76]. The CLASS questionnaire was found to have weak to moderate validity and reliability. Nonetheless, both the PAQ-C and CLASS questionnaire were considered amongst the most promising PA questionnaire for children [76].

\section{Translation of the physical activity questionnaires}

The aim of the translation process was to develop a Dutch version of the PAQ-C that is conceptually equivalent but adapted to represent common Dutch physical activities. The translation process was carried out using a forwardbackward translation technique [77-79]. First, three researchers, native Dutch speakers and fluent in English, produced independent forward translations of the original PAQ-C and CLASS questionnaire. Then, the researchers and the project manager produced a reconciled Dutch version based on the forward translations and the original questionnaires, and an English report documenting the synthesis process, the issues addressed, and how they were resolved. Then, a native English and fluently Dutch speaking translator, who was blind to the original version, translated this reconciled Dutch version back into English. One of the researchers and the project manager compared the back-translated version with the original version, assessing inaccuracies, misunderstandings or mistranslations, and 
produced a prefinal version. The project manager and all involved researchers replaced PA items that are rarely conducted by Dutch children (e.g., Australian football, cross-country skiing) by items that are more commonly practiced (e.g., playing tennis, badminton, practicing judo). This version was administered to 10 Dutch children of primary school age (i.e., the target population) checking the comprehensibility of each item. As there were no ambiguities reported, we concluded that the adapted version retained its equivalence in an applied situation. The final PA questionnaire used in this study is provided in the Appendix (see additional file 1).

\section{B. Physical fitness test battery}

A physical fitness test battery was developed using the evidence-based recommendations of the ALPHA healthrelated fitness test battery for children and adolescents [80] and the Eurofit Fitness test Battery [81]. We successively assessed anthropometry, blood pressure, maximum muscle strength, explosive muscle strength and aerobic fitness.

\section{Anthropometry}

Height and weight were measured with the children dressed in light sportswear. Height was measured to the nearest millimetre using a Leicester portable height measure (Seca), and weight to the nearest 100 gram using a Marsden weighing scale, model MS-4102.

\section{Blood pressure}

Blood pressure was measured two times on the right arm in a sitting position after a few minutes rest. If the difference between the measurements was more than $10 \mathrm{mmHg}$ for either systolic or diastolic pressure, a third measurement was obtained. The device used was the Omron 705 IT (Omron Healthcare Inc, Bannockburn, IL, USA) with an appropriate sized cuff. Outcome measures were systolic pressure (SP), diastolic pressure (DP), and mean arterial pressure (MAP), all expressed in mmHg. MAP was calculated using the following equation: $\mathrm{MAP}=\mathrm{DP}+1 / 3$ (SP-DP) [82].

\section{Muscular strength}

With the standing broad jump (SBJ) and hand grip strength test we assessed explosive muscle strength and maximum muscle strength, respectively.

In the SBJ test, the child attempts to jump as far as possible with feet together. From a starting position immediately behind a line with feet slightly apart, the child jumps using both feet with take-off and landing, swinging the arms and bending the knees to provide forward drive. The distance was measured from the take-off line to the point where the back of the heel nearest to the take-off line lands, and reported in centimetres. The test was repeated twice, and the best score retained.
Hand grip strength was measured using a hand dynamometer, with the scores recorded in kilograms $(\mathrm{kg})$. The reported precision is $0.5 \mathrm{~kg}$. The test was performed twice (alternately with both hands), with the dynamometer adjusted to the age- and gender-specific optimal grip span, as this seems the most appropriate protocol to evaluate maximal hand grip strength in children [83].

The SBJ test seems to be the most valid test assessing lower body muscular strength compared to other muscular strength tests (i.e., bent and extended arm hang, squat jump, countermovement jump, Abalakov jump), showing the highest associations with isokinetic parameters [80]. In addition, Castro-Piñero et al. concluded that the SBJ test can be considered a general index of lower body muscular fitness in children, based on a strong association with other lower body muscular strength tests $\left(R^{2}=0.83-0.86\right)$, as well as with upper body muscular strength tests $\left(R^{2}=0.7-0.9\right)$ [67]. Milliken et al. analysed the association between hand grip strength and chest press in children aged 7-12 years and found that the hand grip strength test is valid to assess upper body maximal strength $\left(R^{2}=0.70\right)$ [84].

\section{Aerobic fitness}

We measured aerobic fitness using the 20 meter multistage shuttle run test (20-m MSRT); a simple non-invasive, valid and reliable field test providing an estimate of maximal cardiorespiratory capacity [85]. The test was conducted as described by Léger et al. [86] On an outdoor field, children were required to run between two lines $20 \mathrm{~m}$ apart, while keeping pace with beeps emitted from a pre-recorded CD. The initial speed was set at $8.5 \mathrm{~km} \cdot \mathrm{h}^{-1}$ $\left(2.4 \mathrm{~m} \cdot \mathrm{s}^{-1}\right)$, increasing by $0.5 \mathrm{~km} \cdot \mathrm{h}^{-1}\left(0.1 \mathrm{~m} \cdot \mathrm{s}^{-1}\right)$ with each stage thereafter (one stage takes one minute). Children were instructed to run in a straight line, to pivot and turn on completing a shuttle, and to pace themselves in accordance with the beeps. The test ended when the child failed to reach the end line concurrent with the beeps on two consecutive occasions. The children were verbally encouraged by the researchers to run for as long as possible throughout the course of the test. The last completed half-stage of the 20-m MSRT was recorded and used as a valid proxy for aerobic fitness $[87,88]$.

The 20-m MSRT has several advantages over other field tests, such as tests that cover as much distance as possible in a set time [89], or tests that cover a set distance in the fastest time possible [90]. First, the 20-m MSRT has a graded physiological response and the absence of individual pace control $[91,92]$. Second, it can be administered in a relatively small space and is therefore easy to implement without extensive facilities. Third, children are known for their frequent stops, starts, and turns in their daily PA. Therefore, it may be a more relevant test than a continuous directional run. 


\section{Accelerometry}

Accelerometers have shown to provide reliable estimates of overall PA, sedentary behavior and PA-related energy expenditure among children [93,94]. In this study, PA and sedentary behavior were objectively assessed using two models of Actigraph (ActiGraph, LLC, Fort Walton Beach, FL) accelerometers, namely triaxial Actitrainers (dimensions: $8.6 \mathrm{~cm} \times 3.3 \mathrm{~cm} \times 1.5 \mathrm{~cm}$, weight: 51 grams) and GT3Xs (dimensions: $3.8 \mathrm{~cm} \times 3.7 \mathrm{~cm} \times 1.8 \mathrm{~cm}$, weight: 27 grams). These are omnidirectional accelerometers, sensitive to movement in all directions.

Researchers distributed the accelerometers face-to-face at the end of the physical fitness test battery. Information about accelerometer use was given to the children and parents orally. Researchers placed the accelerometer to the children's waist using an elastic waistband, and they told the children not to remove the device for 7 days except during sleeping, swimming and bathing. Additionally, children and parents received a brochure with information about accelerometer use and a compliance log. Children had to self-complete this compliance $\log$ for the duration of the accelerometer data collection, as this is an effective, low cost method to increase compliance [95]. Each day, the children recorded the time they got up and went to bed, whether or not it was a school day, and whether the accelerometer was removed during the day, and if so, for what reason. After the proposed wearing period, the devices were collected at the child's home by the researchers. Downloading the data from accelerometers was done as soon as possible on the same computer where it was initialized to prevent disturbances that can be caused by the time offset between computers [96].

The accelerometer signal is summarized over a userdefined period of time, called epoch, into what are called counts. The higher the number of counts, the higher the intensity of PA. As children tend to have short bursts of PA [97], we selected an epoch length of 15 seconds to accurately capture this spasmodic PA pattern [98]. Non-wearing time was defined as more than 20 minutes of consecutive zero counts. Wearing time was calculated by subtracting non-wearing time from 24 hours. To capture a representative portion of daily PA, only days with at least 10 hours of wearing time were considered valid [99]. Children who had at least three valid weekdays and one valid weekend day were included in further data analysis [100]. Based on the cut-off values of Treuth et al. we defined minutes spent in sedentary, light, moderate and vigorous activity, as $<100,100-2999,3000-5199$ and $\geq 5200$ counts per minute (c.p.m.), respectively [101].

\section{Statistical analysis}

Data will be presented as means $\pm S D$ for continuous variables, and as percentages for categorical variables.
For every primary outcome, its association with standardized birth weight and infant growth will be assessed using multivariable linear regression analysis. First, birth weights and infant growth trajectories will be dichotomized as normal vs. low birth weight and normal vs. accelerated infant growth, respectively, and analyzed together in a linear regression analysis to account for mutual interference. To assess whether the effect of low birth weight and accelerated infant growth exceeds the sum of each exposure separately, we will subsequently add an interaction term of birth weight with infant growth to the model. A $\mathrm{p}$-value less than 0.10 for the interaction term is considered indicative of effect modification, after which a subgroup analysis will be performed with the children divided into four subgroups (normal birth weight and normal infant growth; low birth weight and normal infant growth; normal birth weight and accelerated infant growth; low birth weight and accelerated infant growth).

A scatterplot will be employed to identify potential linear associations of either birth weight or infant growth with the outcome variable. If the scatterplot suggests a linear association of either birth weight or infant growth with the outcome, we will additionally run the analysis with the respective dichotomized variable replaced by its continuous equivalent.

The model will be adjusted for potential confounding, by addition of the potential confounders group-wise in a multivariable linear regression analysis. The first group of potential confounders are subject-specific variables (gender, current age, height, BMI, gestational age, Apgar score), the second are family-specific variables (socioeconomic status (defined as maternal level as education), maternal age, maternal height, maternal pre-pregnancy BMI). Effect modification by gender will be evaluated by addition of an interaction term of gender with either birth weight or infant growth.

\section{Validity assessment of the questionnaire}

To assess the construct validity of the modified PA questionnaire, PAQ-C summary scores will be examined as originally constructed (the average of the nine questions) [69]. Pearson's correlation coefficient between the PAQ-C summary score and accelerometer-assessed moderate to vigorous PA (MVPA) will be calculated, to assess the construct validity of the PA questionnaire compared to accelerometry. In addition, the common leisure and sports activities assessed in the first question are assigned metabolic equivalent units (METs) based on the MET values given in the recently updated 2011 Compendium of Physical Activities [102]. These activities are classified as sedentary $(<2$ MET), light (2-4.5 MET), moderate (4.6-6.5 MET) or vigorous (more than 6.5 MET) PA, and grouped together to assess the daily time spent in each PA level. Agreement between self-reported minutes in MVPA and minutes in MVPA 
according to accelerometry data will be examined using the Bland-Altman procedure [103]. A similar approach will be used to assess the agreement between self-reported and accelerometry assessed sedentary time. The Bland-Altman procedure plots the differences between the self-reported and accelerometry data against their mean, where $\pm 1.96 \mathrm{SD}$ of the differences provides an interval within which $95 \%$ of the differences between the two sets of measurements are predicted to fall. A higher level of agreement is illustrated by a mean difference closer to zero and a smaller range of the $95 \%$ confidence interval.

\section{Discussion}

Although low birth weight and accelerated infant growth have been consistently linked to childhood and adult obesity $[8,15]$, the underlying disturbances in energy balance regulation still remain poorly understood. The present study focuses on the developmental origins of physical fitness, physical activity and sedentary behavior in 8-9 year old children, as this might partly explain the higher obesity and cardiovascular risk associated with low birth weight and accelerated infant growth. In addition, this study provides the opportunity for a validation study of a linguistic and cross-cultural translated PAQ-C and CLASS questionnaire compared to accelerometer data. If the validation study suggests that the translated questionnaire is a valid tool to assess PA and sedentary behavior in this subgroup, it may be used in a later stage of the ABCD study, to assess PA and sedentary behavior in our entire birth cohort.

To our knowledge, this study is the first prospective cohort study addressing the association of both birth weight and infant growth with objectively assessed PA and sedentary behavior, aerobic fitness and muscular strength in later childhood. A major strength of this study is that it is conducted within the framework of the ABCD study, a prospective cohort study with extensive data on birth outcome, growth patterns, and lifestyle factors, amongst others. This provides the opportunity to control for a broad range of potential confounders, like BMI, gestational age, Apgar score, maternal age, maternal pre-pregnancy BMI, and socio-economic status. All these variables are prospectively collected and assessed during the course of the ABCD study [60].

A limitation of this study is that only children of Dutch ethnicity are included, to exclude confounding by ethnicity. As there are known ethnic differences in both obesity risk [104,105] and PA levels and sedentary behavior [106,107], the results might not be applicable to other ethnic groups. In addition, selective nonresponse in this study may lead to an oversampling of physically fit children, as these children might be more willing to participate in a study on PA and fitness. Both these aspects hamper the generalizability of the results.
In this study design, and in many others, birth weight below the $10^{\text {th }}$ percentile is used to identify intrauterine growth retardation [108]. However, this is only a very crude indicator [109], and there is increasing evidence that insults during fetal life can have long-term consequences independently of birth weight [110]. On the other hand, a low birth weight subject could be small at birth because of genetic reasons or maternal characteristics, and indeed have had a perfectly well-nourished fetal life. The use of customized growth standards to identify low birth weight subjects, in line with Gardosi's recommendations [61], may partly avoid misclassification. Nonetheless, instead of a 'present' or 'absent' definition of low birth weight, it is considered more informative to assess whether there is a continuous association of outcome with birth weight [110]. In fact, substantial epidemiological data indicate there is a continuous inverse association of birth weight with certain chronic diseases [7,9,111]. In line with this, if we find a linear association of birth weight and/or infant growth with the outcome measure, we will report the results of linear regression analyses with birth weight both dichotomized as well as a continuous variable.

While the significance of infant growth in the predisposition to adult disease has extensive support from observational studies, it is not clear whether the detrimental adult outcomes (obesity and cardiovascular disease) are related to a specific time window. Different studies vary widely in definition and duration of accelerated growth, with the period of growth evaluated being as short as 1 week [112] up to the first 7 years of life [18]. A consistent age interval used in several studies was 0-1 year and 0-2 years, all of which also used the +0.67 weight-for-age SD score variation cut-off point as a definition for accelerated growth [15]. In line with the recommendations [15] and recent other studies [62-65], we will adopt the 0-1 year age interval and the $0.67 \mathrm{SD}$ score variation for the period of infant growth and the definition of rapid growth, respectively.

There are consistent relations between PA and fitness status in adults and children [42]. Physical fitness is in part determined by PA patterns over recent weeks or months, although the improvement in fitness to a standard exercise dose varies widely and is considered predisposed [113]. It is stated that such individual predisposition reflects genetic traits [47], but the programming of PA patterns based on early life experiences offers an alternative explanation. Conversely, higher levels of physical fitness, especially aerobic fitness, may promote higher PA levels. As sports and active play may be more easy, successful and rewarding for the physically fit, these children may engage in PA more often. This poses individuals at the lower end of the activity and fitness distribution at considerable risk of a downward spiral of inactivity leading to reduced fitness and reduced fitness leading to less activity. Given the strong and consistent inverse relations of physical fitness 
and physical activity with obesity and cardiovascular risk profile, this will have detrimental effects on later health $[42,53]$.

If the present study indeed shows that physical fitness, PA and sedentary behavior are significantly associated with birth weight and infant growth, further assessment of the potential mechanisms underlying these associations is required. For example, animal studies provide evidence that sympathetic nervous system (SNS) function is likely to be involved in the developmental origins of later obesity risk. Perinatal insults have been reported to alter SNS development, which may persist throughout life [114]. In human studies, an inverse association between birth weight and SNS activity in middle-aged adults [115], young adults [116] and adolescents [117] was found, although a study in neonates born small for gestational age found no such association [118]. SNS hyperactivity may contribute to obesity through increased food intake [119], altered glucose metabolism [120], and decreased energy expenditure [121]. Whether these developmentally-induced variations in SNS function influence PA and fitness remains to be investigated. In addition, alterations in body composition are widely believed to contribute to the pathogenesis of obesity and its complications. Low birth weight has been linked to lower adult and childhood muscle mass [48] and altered muscle metabolism [122]. To what extent these developmental influences on skeletal muscle mass and function explain variations in physical fitness and activity needs further investigation.

In conclusion, this study examines developmentallyinduced variations in physical fitness, PA and sedentary behavior in children aged 8-9 years and contributes to an improved understanding of the perinatal influences on energy balance regulation. This knowledge may guide future studies in the field of developmental origins of obesity and related diseases. In addition, the results might initiate preventive public health strategies, as the early promotion of an active lifestyle may be an effective and efficient way to attenuate later disease risk in low birth weight and infant growth accelerated children.

\section{Additional file}

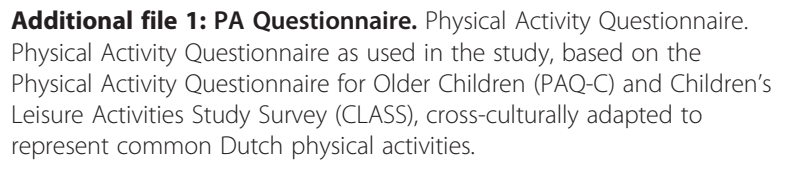

\section{Abbreviations}

ABCD: Amsterdam born children and their development; BMl: Body mass index; CLASS: Children's leisure activities study survey; c.p.m.: Counts per minute; DOHaD: Developmental origins of health and disease; DP: Diastolic pressure; kg: Kilograms; MAP: Mean arterial pressure; MET: Metabolic equivalent units; MVPA: Moderate to vigorous physical activity; PA: Physical activity; PAQ-C: Physical activity questionnaire for older children; SBJ: Standing broad jump; SD: Standard deviation; SNS: Sympathetic nervous system; SP: Systolic pressure; 20-m MSRT: 20 meter multistage shuttle run test.

\section{Competing interests}

The authors declare that they have no competing interests.

\section{Authors' contributions}

AD: Conception and design of study. Drafting the article and revision on critically important intellectual content. Final approval of the manuscript version to be published. MC: Conception and design of study. Drafting the article and revision on critically important intellectual content. Final approval of the manuscript version to be published. TV: Conception and design of study. Establishing and coordinating the ABCD-birth cohort. Drafting the article and revision on critically important intellectual content. Final approval of the manuscript version to be published. RG: Conception and design of study. Establishing the ABCD-birth cohort. Drafting the article and revision on critically important intellectual content. Final approval of the manuscript version to be published. All authors read and approved the final manuscript.

\section{Author details}

${ }^{1}$ Department of Pediatrics, EMGO Institute for Health \& Care Research, VU University Medical Center, Amsterdam, the Netherlands. ${ }^{2}$ Institute for Cardiovascular Research VU, VU University Medical Center, Amsterdam, the Netherlands. ${ }^{3}$ Department of Public and Occupational Health, EMGO institute for Health \& Care Research, VU University Medical Center, Amsterdam, the Netherlands. ${ }^{4}$ Department of Public Health, Academic Medical Centre, University of Amsterdam, Amsterdam, the Netherlands.

Received: 28 June 2013 Accepted: 1 July 2013

Published: 9 July 2013

\section{References}

1. Barker DJ, Osmond C: Infant mortality, childhood nutrition, and ischaemic heart disease in England and Wales. Lancet 1986, 1(8489):1077-1081.

2. Barker DJ, Winter PD, Osmond C, Margetts B, Simmonds SJ: Weight in infancy and death from ischaemic heart disease. Lancet 1989, 2(8663):577-580.

3. Frankel S, Elwood P, Sweetnam P, Yarnell J, Smith GD: Birthweight, body-mass index in middle age, and incident coronary heart disease. Lancet 1996, 348(9040):1478-1480.

4. Rich-Edwards JW, Stampfer MJ, Manson JE, Rosner B, Hankinson SE, Colditz GA, Willett WC, Hennekens $\mathrm{CH}$ : Birth weight and risk of cardiovascular disease in a cohort of women followed up since 1976. BMJ 1997, 315(7105):396-400.

5. Lawlor DA, Ronalds G, Clark H, Smith GD, Leon DA: Birth weight is inversely associated with incident coronary heart disease and stroke among individuals born in the 1950s: findings from the Aberdeen Children of the 1950s prospective cohort study. Circulation 2005, 112(10):1414-1418.

6. Curhan GC, Willett WC, Rimm EB, Spiegelman D, Ascherio AL, Stampfer MJ: Birth weight and adult hypertension, diabetes mellitus, and obesity in US men. Circulation 1996, 94(12):3246-3250.

7. Huxley RR, Shiell AW, Law CM: The role of size at birth and postnatal catch-up growth in determining systolic blood pressure: a systematic review of the literature. J Hypertens 2000, 18(7):815-831.

8. Yu ZB, Han SP, Zhu GZ, Zhu C, Wang XJ, Cao XG, Guo XR: Birth weight and subsequent risk of obesity: a systematic review and meta-analysis. Obes Rev 2011, 12(7):525-542.

9. Baird J, Kurshid MA, Kim M, Harvey N, Dennison E, Cooper C: Does birthweight predict bone mass in adulthood? A systematic review and meta-analysis. Osteoporos Int 2011, 22(5):1323-1334.

10. Ibanez L, de Zegher F, Potau N: Premature pubarche, ovarian hyperandrogenism, hyperinsulinism and the polycystic ovary syndrome: from a complex constellation to a simple sequence of prenatal onset. $J$ Endocrinol Invest 1998, 21(9):558-566.

11. Wojcik W, Lee W, Colman I, Hardy R, Hotopf M: Foetal origins of depression? A systematic review and meta-analysis of low birth weight and later depression. Psychol Med 2013, 43(1):1-12.

12. Susser E, Neugebauer R, Hoek HW, Brown AS, Lin S, Labovitz D, Gorman JM: Schizophrenia after prenatal famine. Further evidence. Arch Gen Psychiatry 1996, 53(1):25-31. 
13. Gluckman PD, Hanson MA: Developmental Origins of Health and Disease. Cambridge, United Kingdom: Cambridge University Press; 2006.

14. Barker DJ: In utero programming of chronic disease. Clin Sci (Lond) 1998, 95(2):115-128.

15. Monteiro PO, Victora CG: Rapid growth in infancy and childhood and obesity in later life-a systematic review. Obes Rev 2005, 6(2):143-154.

16. Norris SA, Osmond C, Gigante D, Kuzawa CW, Ramakrishnan L, Lee NR, Ramirez-Zea M, Richter LM, Stein AD, Tandon N, et al: Size at birth, weight gain in infancy and childhood, and adult diabetes risk in five low- or middle-income country birth cohorts. Diabetes Care 2012, 35(1):72-79.

17. Eriksson JG, Forsen T, Tuomilehto J, Osmond C, Barker DJ: Fetal and childhood growth and hypertension in adult life. Hypertension 2000, 36(5):790-794

18. Eriksson JG, Forsen T, Tuomilehto J, Winter PD, Osmond C, Barker DJ: Catch-up growth in childhood and death from coronary heart disease: longitudinal study. BMJ 1999, 318(7181):427-431.

19. Gilbert JS, Nijland MJ: Sex differences in the developmental origins of hypertension and cardiorenal disease. Am J Physiol Regul Integr Comp Physiol 2008, 295(6):R1941-R1952.

20. Grigore D, Ojeda NB, Alexander BT: Sex differences in the fetal programming of cardiovascular disease. Gend Med 2008, 5:S121. Suppl A.

21. Goodman E, Dolan LM, Morrison JA, Daniels SR: Factor analysis of clustered cardiovascular risks in adolescence: obesity is the predominant correlate of risk among youth. Circulation 2005, 111(15):1970-1977.

22. Hill JO, Wyatt HR, Peters JC: Energy balance and obesity. Circulation 2012, 126(1):126-132.

23. Belcher BR, Berrigan D, Dodd KW, Emken BA, Chou CP, Spruijt-Metz D: Physical activity in US youth: effect of race/ethnicity, age, gender, and weight status. Med Sci Sports Exerc 2010, 42(12):2211-2221.

24. Verloigne M, Van Lippevelde W, Maes L, Yildirim M, Chinapaw M, Manios Y, Androutsos O, Kovacs E, Bringolf-Isler B, Brug J, et al: Levels of physical activity and sedentary time among 10- to 12-year-old boys and girls across 5 European countries using accelerometers: an observational study within the ENERGY-project. Int J Behav Nutr Phys Act 2012, 9:34.

25. Pate RR, O'Neill JR, Lobelo F: The evolving definition of "sedentary". Exerc Sport Sci Rev 2008, 36(4):173-178.

26. Vickers MH, Gluckman PD, Coveny AH, Hofman PL, Cutfield WS, Gertler A, Breier $\mathrm{BH}$, Harris M: Neonatal leptin treatment reverses developmental programming. Endocrinology 2005, 146(10):4211-4216.

27. Vickers $\mathrm{MH}$, Breier BH, McCarthy D, Gluckman PD: Sedentary behavior during postnatal life is determined by the prenatal environment and exacerbated by postnatal hypercaloric nutrition. Am J Physiol Regul Integr Comp Physiol 2003, 285(1):R271-R273.

28. Bellinger L, Sculley DV, Langley-Evans SC: Exposure to undernutrition in fetal life determines fat distribution, locomotor activity and food intake in ageing rats. Int J Obes (Lond) 2006, 30(5):729-738.

29. Remmers F, de Waal HA D-v: Developmental programming of energy balance and its hypothalamic regulation. Endocr Rev 2011, 32(2):272-311.

30. Lussana F, Painter RC, Ocke MC, Buller HR, Bossuyt PM, Roseboom TJ: Prenatal exposure to the Dutch famine is associated with a preference for fatty foods and a more atherogenic lipid profile. Am J Clin Nutr 2008, 88(6):1648-1652

31. Stein AD, Rundle A, Wada N, Goldbohm RA, Lumey LH: Associations of gestational exposure to famine with energy balance and macronutrient density of the diet at age 58 years differ according to the reference population used. J Nutr 2009, 139(8):1555-1561.

32. Kajantie E, Strang-Karlsson S, Hovi P, Raikkonen K, Pesonen AK, Heinonen K, Jarvenpaa AL, Eriksson JG, Andersson S: Adults born at very low birth weight exercise less than their peers born at term. J Pediatr 2010, 157(4):610-616. 616 e611.

33. Kaseva N, Wehkalampi K, Strang-Karlsson S, Salonen M, Pesonen AK, Raikkonen K, Tammelin T, Hovi P, Lahti J, Heinonen K, et al: Lower conditioning leisure-time physical activity in young adults born preterm at very low birth weight. PLoS One 2012, 7(2):e32430.

34. Rogers M, Fay TB, Whitfield MF, Tomlinson J, Grunau RE: Aerobic capacity, strength, flexibility, and activity level in unimpaired extremely low birth weight $(<0 r=800 \mathrm{~g})$ survivors at 17 years of age compared with termborn control subjects. Pediatrics 2005, 116(1):e58-e65.

35. Hallal PC, Wells JC, Reichert FF, Anselmi L, Victora CG: Early determinants of physical activity in adolescence: prospective birth cohort study. BMJ 2006, 332(7548):1002-1007.
36. Hallal PC, Dumith SC, Ekelund U, Reichert FF, Menezes AM, Victora CG, Wells JC: Infancy and childhood growth and physical activity in adolescence: prospective birth cohort study from Brazil. Int J Behav Nutr Phys Act 2012 9:82.

37. Ridgway CL, Brage S, Sharp SJ, Corder K, Westgate KL, van Sluijs EM, Goodyer IM, Hallal PC, Anderssen SA, Sardinha LB, et al: Does birth weight influence physical activity in youth? A combined analysis of four studies using objectively measured physical activity. PLoS One 2011, 6(1):e16125.

38. Pearce MS, Basterfield L, Mann KD, Parkinson KN, Adamson AJ, Reilly JJ: Early predictors of objectively measured physical activity and sedentary behaviour in 8-10 year old children: the Gateshead Millennium Study. PLoS One 2012, 7(6):e37975.

39. Mattocks C, Deere K, Leary S, Ness A, Tilling K, Blair SN, Riddoch C: Early life determinants of physical activity in 11 to 12 year olds: cohort study. $\mathrm{Br}$ J Sports Med 2008, 42(9):721-724.

40. Campbell CP, Barnett AT, Boyne MS, Soares-Wynter S, Osmond C, Fraser RA, Badaloo AV, Taylor-Bryan C, Forrester TE: Predictors of physical activity energy expenditure in Afro-Caribbean children. Eur J Clin Nutr 2010, 64(10):1093-1100.

41. Andersen LG, Angquist L, Gamborg M, Byberg L, Bengtsson C, Canoy D, Eriksson JG, Eriksson M, Jarvelin MR, Lissner $L$, et al: Birth weight in relation to leisure time physical activity in adolescence and adulthood: meta-analysis of results from 13 nordic cohorts. PLoS One 2009, 4(12):e8192.

42. Cumming S, Riddoch C: Physical activity, physical fitness, and health: current concepts. In , Paediatric Exercise Science and MedicineEdited by Armstrong N, Van Mechelen W. New York: Oxford University Press; 2008:327-338

43. Dennison BA, Straus JH, Mellits ED, Charney E: Childhood physical fitness tests: predictor of adult physical activity levels? Pediatrics 1988, 82(3):324-330

44. Sandvik L, Erikssen J, Thaulow E, Erikssen G, Mundal R, Rodahl K: Physical fitness as a predictor of mortality among healthy, middle-aged Norwegian men. N Engl J Med 1993, 328(8):533-537.

45. Shrier I: Muscle strength and body size and later cerebrovascular and coronary heart disease. Clin J Sport Med 2010, 20(2):131.

46. Grontved A, Ried-Larsen M, Moller NC, Kristensen PL, Froberg K, Brage S, Andersen LB: Muscle strength in youth and cardiovascular risk in young adulthood (the European Youth Heart Study). Br J Sports Med 2013.

47. Montgomery H, Safari L: Genetic Basis of Physical Fitness. Ann Rev Anthropol 2007, 36(1):391-405.

48. Dodds R, Denison HJ, Ntani G, Cooper R, Cooper C, Sayer AA, Baird J: Birth weight and muscle strength: a systematic review and meta-analysis. J Nutr Health Aging 2012, 16(7):609-615.

49. Boreham CA, Murray L, Dedman D, Davey Smith G, Savage JM, Strain JJ: Birthweight and aerobic fitness in adolescents: the Northern Ireland Young Hearts Project. Publ Health 2001, 115(6):373-379.

50. Burns YR, Danks M, O'Callaghan MJ, Gray PH, Cooper D, Poulsen L, Watter P: Motor coordination difficulties and physical fitness of extremelylow-birthweight children. Dev Med Child Neurol 2009, 51(2):136-142.

51. Ortega FB, Labayen I, Ruiz JR, Martin-Matillas M, Vicente-Rodriguez G, Redondo C, Warnberg J, Gutierrez A, Sjostrom M, Castillo MJ, et al: Are muscular and cardiovascular fitness partially programmed at birth? Role of body composition. J Pediatr 2009, 154(1):61-66. e61.

52. Salonen MK, Kajantie E, Osmond C, Forsen T, Yliharsila H, Paile-Hyvarinen M, Barker DJ, Eriksson JG: Developmental origins of physical fitness: the Helsinki Birth Cohort Study. PLoS One 2011, 6(7):e22302.

53. Twisk JW, Ferreira I: Physical activity, physical fitness, and cardiovascular health. In , Paediatric Exercise Science and MedicineEdited by Armstrong N, Van Mechelen W. New York: Oxford University Press; 2008:339-351.

54. Proper Kl, Singh AS, van Mechelen W, Chinapaw MJ: Sedentary behaviors and health outcomes among adults: a systematic review of prospective studies. Am J Prev Med 2011, 40(2):174-182.

55. Van Uffelen JG, Wong J, Chau JY, van der Ploeg HP, Riphagen I, Gilson ND Burton NW, Healy GN, Thorp AA, Clark BK, et al: Occupational sitting and health risks: a systematic review. Am J Prev Med 2010, 39(4):379-388.

56. Lynch BM: Sedentary behavior and cancer: a systematic review of the literature and proposed biological mechanisms. Canc Epidemiol Biomarkers Prev 2010, 19(11):2691-2709.

57. Prentice-Dunn H, Prentice-Dunn S: Physical activity, sedentary behavior, and childhood obesity: a review of cross-sectional studies. Psychol Health Med 2012, 17(3):255-273 
58. Rey-Lopez JP, Vicente-Rodriguez G, Biosca M, Moreno LA: Sedentary behaviour and obesity development in children and adolescents. Nutr Metab Cardiovasc Dis 2008, 18(3):242-251.

59. Chinapaw MJ, Proper Kl, Brug J, van Mechelen W, Singh AS: Relationship between young peoples' sedentary behaviour and biomedical health indicators: a systematic review of prospective studies. Obes Rev 2011, 12(7):e621-e632.

60. van Eijsden M, Vrijkotte TG, Gemke RJ, van der Wal MF: Cohort profile: the Amsterdam Born Children and their Development (ABCD) study. Int J Epidemiol 2011, 40(5):1176-1186.

61. Gardosi J: New definition of small for gestational age based on fetal growth potential. Horm Res 2006, 65(Suppl 3):15-18.

62. Perala MM, Kajantie E, Valsta LM, Holst JJ, Leiviska J, Eriksson JG: Early growth and postprandial appetite regulatory hormone responses. $\mathrm{Br}$ J Nutr 2013:1-10.

63. Webster V, Denney-Wilson E, Knight J, Comino E: Describing the growth and rapid weight gain of urban Australian Aboriginal infants. J Paediatr Child Health 2013, 49(4):303-308.

64. Faienza MF, Brunetti G, Ventura A, D'Aniello M, Pepe T, Giordano P, Monteduro M, Cavallo L: Nonalcoholic Fatty liver disease in prepubertal children born small for gestational age: influence of rapid weight catchup growth. Horm Res Paediatr 2013, 79(2):103-109.

65. Rios-Castillo I, Cerezo S, Corvalan C, Martinez M, Kain J: Risk factors during the prenatal period and the first year of life associated with overweight in 7-year-old low-income Chilean children. Matern Child Nutr 2012.

66. Fjortoft I, Pedersen AV, Sigmundsson H, Vereijken B: Measuring physical fitness in children who are 5 to 12 years old with a test battery that is functional and easy to administer. Phys Ther 2011, 91(7):1087-1095.

67. Castro-Pinero J, Ortega FB, Artero EG, Girela-Rejon MJ, Mora J, Sjostrom M, Ruiz JR: Assessing muscular strength in youth: usefulness of standing long jump as a general index of muscular fitness. J Strength Cond Res 2010, 24(7):1810-1817.

68. Decleration of Helsinki: Ethical Principles for Medical Research Involving Human Subjects. http://www.wma.net/en/30publications/10policies/b3/index.html

69. Kowalski KC, Crocker PRE, Donen RM: The physical activity questionnaire for older children (PAQ-C) and adolescents (PAQ-A) manual. Saskatoon: College of Kinesiology, University of Saskatchewan; 2004.

70. Telford A, Salmon J, Jolley D, Crawford D: Reliability and validity of physical activity questionnaires for children: The Children's Leisure Activities Study Survey (CLASS). Pediatr Exerc Sci 2004, 16(1):64-78.

71. Crocker PR, Bailey DA, Faulkner RA, Kowalski KC, McGrath R: Measuring general levels of physical activity: preliminary evidence for the Physical Activity Questionnaire for Older Children. Med Sci Sports Exerc 1997, 29(10):1344-1349.

72. Janz KF, Lutuchy EM, Wenthe P, Levy SM: Measuring activity in children and adolescents using self-report: PAQ-C and PAQ-A. Med Sci Sports Exerc 2008, 40(4):767-772.

73. Moore JB, Hanes JC Jr, Barbeau P, Gutin B, Trevino RP, Yin Z: Validation of the Physical Activity Questionnaire for Older Children in children of different races. Pediatr Exerc Sci 2007, 19(1):6-19.

74. Voss C, Ogunleye AA, Sandercock GR: Physical Activity Questionnaire for Children and Adolescents: English norms and cut-points. Pediatr Int 2013.

75. Biddle SJ, Gorely T, Pearson N, Bull FC: An assessment of self-reported physical activity instruments in young people for population surveillance: Project ALPHA. Int J Behav Nutr Phys Act 2011, 8:1.

76. Chinapaw MJ, Mokkink LB, van Poppel MN, van Mechelen W, Terwee CB: Physical activity questionnaires for youth: a systematic review of measurement properties. Sports Med 2010, 40(7):539-563.

77. Wild D, Grove A, Martin M, Eremenco S, McElroy S, Verjee-Lorenz A, Erikson P: Principles of Good Practice for the Translation and Cultural Adaptation Process for Patient-Reported Outcomes (PRO) Measures: report of the ISPOR Task Force for Translation and Cultural Adaptation. Value Health 2005, 8(2):94-104.

78. Beaton DE, Bombardier C, Guillemin F, Ferraz MB: Guidelines for the process of cross-cultural adaptation of self-report measures. Spine (Phila Pa 1976) 2000, 25(24):3186-3191.

79. Bullinger M, Alonso J, Apolone G, Leplege A, Sullivan M, Wood-Dauphinee S, Gandek B, Wagner A, Aaronson N, Bech P, et al: Translating health status questionnaires and evaluating their quality: the IQOLA Project approach. International Quality of Life Assessment. J Clin Epidemiol 1998, 51(11):913-923.
80. Ruiz JR, Castro-Pinero J, Espana-Romero V, Artero EG, Ortega FB, Cuenca MM, Jimenez-Pavon D, Chillon P, Girela-Rejon MJ, Mora J, et al: Field-based fitness assessment in young people: the ALPHA health-related fitness test battery for children and adolescents. Br J Sports Med 2011, 45(6):518-524

81. Adam C, Klissouras V, Ravazzolo M, Renson R, Tuxworth W: EUROFIT: European test of physical fitness - Manual. Rome: Rome, Council of Europe, Committee for the Development of Sport; 1988.

82. Haque IU, Zaritsky AL: Analysis of the evidence for the lower limit of systolic and mean arterial pressure in children. Pediatr Crit Care Med J Soc Crit Care Med World Fed Pediatr Intensive Crit Care Soc 2007, 8(2):138-144.

83. Espana-Romero V, Artero EG, Santaliestra-Pasias AM, Gutierrez A, Castillo MJ, Ruiz JR: Hand span influences optimal grip span in boys and girls aged 6 to 12 years. J Hand Surg Am 2008, 33(3):378-384.

84. Milliken LA, Faigenbaum AD, Loud RL, Westcott WL: Correlates of upper and lower body muscular strength in children. J Strength Cond Res 2008, 22(4):1339-1346.

85. Stickland MK, Petersen SR, Bouffard M: Prediction of maximal aerobic power from the 20-m multi-stage shuttle run test. Can J Appl Physiol 2003, 28(2):272-282.

86. Leger LA, Mercier D, Gadoury C, Lambert J: The multistage 20 metre shuttle run test for aerobic fitness. J Sports Sci 1988, 6(2):93-101.

87. Artero EG, Espana-Romero V, Castro-Pinero J, Ortega FB, Suni J, Castillo-Garzon MJ, Ruiz JR: Reliability of field-based fitness tests in youth. Int J Sports Med 2011, 32(3):159-169.

88. Castro-Pinero J, Artero EG, Espana-Romero V, Ortega FB, Sjostrom M, Suni J, Ruiz JR: Criterion-related validity of field-based fitness tests in youth: a systematic review. Br J Sports Med 2010, 44(13):934-943.

89. Cooper KH: The New Aerobics. 27th edition. New York: M. Evans and Company, Inc.; 1970.

90. Kline GM, Porcari JP, Hintermeister R, Freedson PS, Ward A, McCarron RF, Ross J, Rippe JM: Estimation of VO2max from a one-mile track walk, gender, age, and body weight. Med Sci Sports Exerc 1987, 19(3):253-259.

91. Paliczka VJ, Nichols AK, Boreham CA: A multi-stage shuttle run as a predictor of running performance and maximal oxygen uptake in adults. Br J Sports Med 1987, 21(4):163-165.

92. Ramsbottom R, Brewer J, Williams C: A progressive shuttle run test to estimate maximal oxygen uptake. Br J Sports Med 1988, 22(4):141-144

93. Tanaka C, Tanaka S, Kawahara J, Midorikawa T: Triaxial accelerometry for assessment of physical activity in young children. Obesity (Silver Spring) 2007, 15(5):1233-1241.

94. Basterfield L, Adamson AJ, Pearce MS, Reilly JJ: Stability of habitual physical activity and sedentary behavior monitoring by accelerometry in 6- to 8-year-olds. J Phys Act Health 2011, 8(4):543-547.

95. Sirard JR, Slater ME: Compliance with wearing physical activity accelerometers in high school students. J Phys Act Health 2009, 6(Suppl 1):S148-S155.

96. Yildirim M, Verloigne $M$, de Bourdeaudhuij I, Androutsos O, Manios Y, Felso $R$, Kovacs E, Doessegger A, Bringolf-Isler B, te Velde SJ, et al: Study protocol of physical activity and sedentary behaviour measurement among schoolchildren by accelerometry-cross-sectional survey as part of the ENERGY-project. BMC Publ Health 2011, 11:182.

97. Bailey RC, Olson J, Pepper SL, Porszasz J, Barstow TJ, Cooper DM: The level and tempo of children's physical activities: an observational study. Med Sci Sports Exerc 1995, 27(7):1033-1041.

98. McClain JJ, Abraham TL, Brusseau TA Jr, Tudor-Locke C: Epoch length and accelerometer outputs in children: comparison to direct observation. Med Sci Sports Exerc 2008, 40(12):2080-2087.

99. Colley R, Connor Gorber S, Tremblay MS: Quality control and data reduction procedures for accelerometry-derived measures of physical activity. Health Rep 2010, 21(1):63-69.

100. Trost SG, Mclver KL, Pate RR: Conducting accelerometer-based activity assessments in field-based research. Med Sci Sports Exerc 2005 37(11 Suppl):S531-S543.

101. Treuth MS, Schmitz K, Catellier DJ, McMurray RG, Murray DM, Almeida MJ, Going S, Norman JE, Pate R: Defining accelerometer thresholds for activity intensities in adolescent girls. Med Sci Sports Exerc 2004, 36(7):1259-1266.

102. Ainsworth BE, Haskell WL, Herrmann SD, Meckes N, Bassett DR Jr, Tudor-Locke C, Greer JL, Vezina J, Whitt-Glover MC, Leon AS: 2011 Compendium of Physical Activities: a second update of codes and MET values. Med Sci Sports Exerc 2011, 43(8):1575-1581. 
103. Bland JM, Altman DG: Statistical methods for assessing agreement between two methods of clinical measurement. Lancet 1986, 327(8476):307-310.

104. Staiano AE, Katzmarzyk PT: Ethnic and sex differences in body fat and visceral and subcutaneous adiposity in children and adolescents. Int Obes (Lond) 2012, 36(10):1261-1269.

105. Fredriks AM, Van Buuren S, Sing RA, Wit JM, Verloove-Vanhorick SP: Alarming prevalences of overweight and obesity for children of Turkish, Moroccan and Dutch origin in The Netherlands according to international standards. Acta Paediatr 2005, 94(4):496-498.

106. Gortmaker SL, Lee R, Cradock AL, Sobol AM, Duncan DT, Wang YC: Disparities in youth physical activity in the United States: 2003-2006. Med Sci Sports Exerc 2012, 44(5):888-893.

107. van Rossem L, Vogel I, Moll HA, Jaddoe WW, Hofman A, Mackenbach JP, Raat $\mathrm{H}$ : An observational study on socio-economic and ethnic differences in indicators of sedentary behavior and physical activity in preschool children. Prev Med 2012, 54(1):55-60.

108. Pollack RN, Divon MY: Intrauterine growth retardation: definition, classification, and etiology. Clin Obstet Gynecol 1992, 35(1):99-107.

109. Miller HC, Hassanein K: Diagnosis of impaired fetal growth in newborn infants. Pediatrics 1971, 48(4):511-522.

110. Preedy VR, Rinaudo P, Delle Piane L, Revelli A: Low Birth Weight, A Marker of Intrauterine Stress and Adult Disease. In Handbook of Growth and Growth Monitoring in Health and Disease. Edited by Preedy VR. New York: Springer New York; 2012:325-341.

111. Newsome CA, Shiell AW, Fall CH, Phillips DI, Shier R, Law CM: Is birth weight related to later glucose and insulin metabolism?-A systematic review. Diabet Med 2003, 20(5):339-348.

112. Stettler N, Stallings VA, Troxel AB, Zhao J, Schinnar R, Nelson SE, Ziegler EE, Strom BL: Weight gain in the first week of life and overweight in adulthood: a cohort study of European American subjects fed infant formula. Circulation 2005, 111(15):1897-1903.

113. Blair SN, Cheng Y, Holder JS: Is physical activity or physical fitness more important in defining health benefits? Med Sci Sports Exerc 2001, 33(6 Suppl):S379-S399. discussion S419-320.

114. Young JB: Developmental origins of obesity: a sympathoadrenal perspective. Int J Obes (Lond) 2006, 30(Suppl 4):S41-S49.

115. Phillips DI, Barker DJ: Association between low birthweight and high resting pulse in adult life: is the sympathetic nervous system involved in programming the insulin resistance syndrome? Diabet Med 1997, 14(8):673-677.

116. Weitz G, Wellhoener P, Heindl S, Fehm HL, Dodt C: Relationship between metabolic parameters, blood pressure, and sympathoendocrine function in healthy young adults with low birth weight. Exp Clin Endocrinol Diabetes 2005, 113(8):444-450.

117. IJzerman RG, Stehouwer CD, de Geus EJ, van Weissenbruch MM, de Waa HA D-V, Boomsma DI: Low birth weight is associated with increased sympathetic activity: dependence on genetic factors. Circulation 2003, 108(5):566-571.

118. Schaffer L, Burkhardt T, Muller-Vizentini D, Rauh M, Tomaske M, Mieth RA, Bauersfeld $U$, Beinder E: Cardiac autonomic balance in smallfor-gestational-age neonates. Am J Physiol Heart Circ Physiol 2008, 294(2):H884-H890

119. Young JB, Shimano Y: Effects of rearing temperature on body weight and abdominal fat in male and female rats. Am J Physiol 1998, 274(2 Pt 2):R398-R405.

120. Phillips DI, Matthews SG: Is perinatal neuroendocrine programming involved in the developmental origins of metabolic disorders? World J Diabetes 2011, 2(12):211-216.

121. Bachman ES, Dhillon H, Zhang CY, Cinti S, Bianco AC, Kobilka BK, Lowell BB: betaAR signaling required for diet-induced thermogenesis and obesity resistance. Science 2002, 297(5582):843-845.

122. Yates DT, Macko AR, Nearing M, Chen X, Rhoads RP, Limesand SW: Developmental programming in response to intrauterine growth restriction impairs myoblast function and skeletal muscle metabolism. J Pregnancy 2012, 2012:631038.

doi:10.1186/1471-2431-13-102

Cite this article as: van Deutekom et al.: Study protocol: the relation of birth weight and infant growth trajectories with physical fitness, physical activity and sedentary behavior at 8-9 years of age - the ABCD study. BMC Pediatrics 2013 13:102.

\section{Submit your next manuscript to BioMed Central and take full advantage of:}

- Convenient online submission

- Thorough peer review

- No space constraints or color figure charges

- Immediate publication on acceptance

- Inclusion in PubMed, CAS, Scopus and Google Scholar

- Research which is freely available for redistribution 